\title{
Mycoloop: chytrids in aquatic food webs
}

\author{
${\text { Maiko Kagami }{ }^{1} \text {, Takeshi Miki }{ }^{2} \text { and Gaku Takimoto }}^{1}$ \\ 1 Faculty of Science, Toho University, Funabashi, Japan \\ 2 Institute of Oceanography, National Taiwan University, Taipei, Taiwan
}

\section{Edited by:}

Télesphore Sime-Ngando, Centre

National de la Recherche

Scientifique, France

Reviewed by:

Nathalie Niquil, Centre National de la Recherche Scientifique, France

Bas Ibelings, University of Geneva,

Switzerland

*Correspondence:

Maiko Kagami, Department of Environmental Science, Faculty of

Science, Toho University, 2-2-1

Miyama, Funabashi, Chiba 274-8510, Japan

e-mail:kagami@env.sci.toho-u.ac.jp
Parasites are ecologically significant in various ecosystems through their role in shaping food web structure, facilitating energy transfer, and controlling disease. Here in this review, we mainly focus on parasitic chytrids, the dominant parasites in aquatic ecosystems, and explain their roles in aquatic food webs, particularly as prey for zooplankton. Chytrids have a free-living zoosporic stage, during which they actively search for new hosts. Zoospores are excellent food for zooplankton in terms of size, shape, and nutritional quality. In the field, densities of chytrids can be high, ranging from $10^{1}$ to $10^{9}$ spores $\mathrm{L}^{-1}$. When large inedible phytoplankton species are infected by chytrids, nutrients within host cells are transferred to zooplankton via the zoospores of parasitic chytrids. This new pathway, the "mycoloop," may play an important role in shaping aquatic ecosystems, by altering sinking fluxes or determining system stability. The grazing of zoospores by zooplankton may also suppress outbreaks of parasitic chytrids. A food web model demonstrated that the contribution of the mycoloop to zooplankton production increased with nutrient availability and was also dependent on the stability of the system. Further studies with advanced molecular tools are likely to discover greater chytrid diversity and evidence of additional mycoloops in lakes and oceans.

Keywords: parasitic fungi, chytridiomycota, diatom, daphnia, mycoloop, indirect mutualism, stability, trophic transfer

\section{ECOLOGICAL SIGNIFICANCE OF PARASITES}

Parasites are important components of ecological communities (Thomas et al., 2005; Hatcher and Dunn, 2011). They have the potential to regulate host populations, mediate interspecific competition between hosts and other species, maintain genetic polymorphism and biodiversity, and affect community structure. Nevertheless, the effects of parasites and diseases on food webs and ecosystem dynamics have been neglected until recently (Polis and Strong, 1996; Marcogliese and Cone, 1997). New research suggests that parasites have the potential to alter food-web topology, stability, interaction strength and energy flow (Lafferty, 2006; Kuris et al., 2008; Lafferty et al., 2008).

Parasites commonly function as prey within ecosystems (Johnson et al., 2010; Thieltges et al., 2013). There are two main ways in which parasites become prey. Predators can either consume the infected hosts of parasites (concomitant predation) or their free-swimming life stage (Johnson et al., 2010). Many aquatic parasites including viruses, chytrids, trematodes, and nematodes, have a free-swimming stage that may be subject to predation (Gonzalez and Suttle, 1993; Kagami et al., 2004; Kuris et al., 2008; Johnson et al., 2010). The Chytridiomycota (chytrids) are one of the dominant groups of parasites in aquatic ecosystems. The free-living zoosporic stage of chytrids actively searches for and infects host cells, extracting nutrients and developing into mature sporangia that release new zoospores (Canter, 1967; Figure 1). There are more than 700 species of chytrids known to infect phytoplankton, zooplankton, fungi, plants, and invertebrate animals (Sparrow, 1960; Gleason et al., 2008). Here in this review, we mainly focus on parasitic chytrids that infect phytoplankton, and explain their roles in aquatic food webs as prey for zooplankton through the "mycoloop" pathway (Kagami et al., 2007a).

\section{CHYTRIDS ZOOSPORES AS PREY FOR ZOOPLANKTON: FOOD QUALITY AND OUANTITY, AND THE MYCOLOOP}

Predation of parasites can be beneficial to predators if they can gain energy and nutrition from parasites. Chytrid zoospores are a good food source for zooplankton in terms of size and shape (Kagami et al., 2004). In addition, zoospores are rich in polyunsaturated fatty acids (PUFAs) and cholesterol, which are essential for the growth of crustaceans (Kagami et al., 2007b). Zooplankton, such as cladocerans (Daphnia) and copepods, are able to grow by acquiring important supplementary nutrients from a diet of zoospores (Kagami et al., 2007b, 2011). Thus, chytrids may improve zooplankton production and enhance trophic transfer.

Many recent studies suggest that parasite biomass is not negligible, and may in fact be often significantly high (Kuris et al., 2008). The abundance of chytrids in aquatic systems has been found to be much higher than traditionally thought. Because morphological identification of chytrid zoospores is difficult, attempts have been made to use the fluorescent stains to count the density of chytrid zoospores in lakes (Kudoh, 1990). Recently, molecular techniques, such as CARD-FISH (Jobard et al., 2010) and Real-Time qPCR (Lefevvre et al., 2010) have been applied to estimate zoospore abundance in field samples and have detected zoospore concentrations of $10^{1}-10^{6}$ spores $\mathrm{L}^{-1}$ (Table 1 ).

Compared to quantifying the abundance of zoospores, sporangia are much easier to count because they are attached to host phytoplankton cells. Using prevalence of infection and host cell 


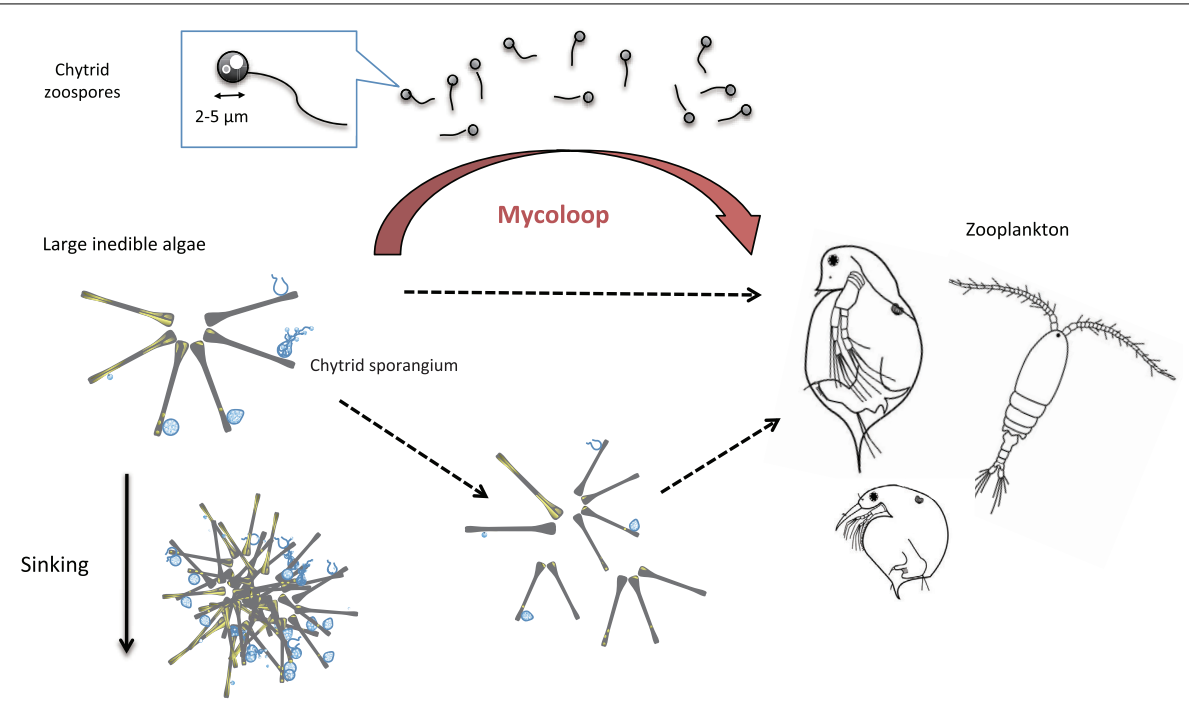

FIGURE 1 | Diagram of "mycoloop." Parasitic chytrids can transfer material from large inedible phytoplankton to zooplankton. Chytrids zoospores are excellent food for zooplankton in terms of size $(2-5 \mu \mathrm{m}$ in diameter), shape, nutritional quality (rich in PUFAs and cholesterols). Large colonies of host phytoplankton may also be fragmented by chytrid infections and become edible to zooplankton. On the other hand, infected host colonies may remain inedible to Daphnia, or even become less edible due to the aggregate formation of cells. Those aggregations may sink faster, and affect material cycling in lakes. density data from the literature, we determined the density of sporangia to be $10^{1}-10^{8}$ spores $\mathrm{L}^{-1}$ in field surveys (Table 1). The result indicated that direct counts of zoospores in the field may underestimate the real densities. By using the zoospore per sporangia conversion factors determined by previous studies (13-28 zoospores per sporangium, Sen, 1988; 4-25 zoospores per sporangium, Bruning, 1991), or the zoospore per sporangium biovolume conversion (0.166 per $\mu \mathrm{m}^{3}$ empty sporangium volume, Bruning, 1991), we can roughly estimate that zoospore abundance could actually reach more than $10^{9}$ zoospores $\mathrm{L}^{-1}$ in the field. It should be noted that lowest abundance of zoospore can be 10 spores $\mathrm{L}^{-1}$, or even zero. This indicates that the potential importance of mycoloop may vary with seasons and lakes.

Molecular studies have also revealed that chytrid zoospore may often be miscounted as small heterotrophic nano-flagellates (HNF), due to similar forms and sizes (Sime-Ngando et al., 2011). A significant portion of small eukaryotes $(0.6-5 \mu \mathrm{m})$ was recently found to be chytrid zoospores in freshwater lakes (11-23\%, Lefèvre et al., 2007; 30\% Lepère et al., 2008). In addition, CARD-FISH identified $5-60 \%$ of unknown flagellates as chytrids zoospores (Jobard et al., 2010). In aquatic ecosystems, most small heterotrophic eukaryotes $(<5 \mu \mathrm{m})$ are considered to play a role in microbial food webs by acting as predators of bacteria and bacterium-sized phytoplankton (Sherr and Sherr, 1983). In contrast, chytrids consume phytoplankton directly as parasites, and they do not eat bacteria. These findings require that we should revise our understanding of microbial food webs.

Zoospores may become particularly important to Daphnia when large inedible phytoplankton species, such as the diatom Asterionella, dominate the phytoplankton community. Large phytoplankton species are quite resistant to grazing by zooplankton such as Daphnia (Knisely and Geller, 1986; Kagami et al., 2002).
However, if large inedible phytoplankton species are infected by chytrids, then nutrients within host cells are consumed by chytrids and can be grazed by Daphnia. This new pathway has been dubbed the "mycoloop" since nutrients from large inedible algae are transferred to zooplankton via the zoospores of parasitic chytrids (Kagami et al., 2007a).

Trophic transfer efficiency from host algae to chytrids is an essential parameter to examine the importance of mycoloop in the field. The transfer efficiencies of carbon, nitrogen, and phosphorus (CNP) from host Asterionella populations to freeswimming zoospores were estimated to be $6-9 \%$ in the laboratory experiment, when the prevalence of infection was about $60 \%$ (Kagami et al., 2007b). Those efficiencies were population based, and may become even higher if the prevalence of infection may exceed $90 \%$. While, a single zoospore can use the host tissues quite efficiently because chytrid can directly consume host nutrients by entering through a germ tube (Van Donk and Ringelberg, 1983). CNP concentrations in a single zoospore (10.7 pg C, 0.6 pg N, 2.4 pg P per zoospore, Kagami et al., 2007b) are comparable to $20 \%$ of those in single host cell, indicating just five zoospores may be enough to exploit all algal tissues. 20\% must be overestimated, if we consider the range of zoospores per sporangia (4-25 zoospores per sporangium, Bruning, 1991). We need to measure the CNP concentrations of zoospores and host cells, and number of zoospores per sporangium accurately with different species and conditions. From these estimates, we can examine how important chytrid zoospores may be as a food source for zooplankton in the field, in comparison to other possible food sources. In addition, such estimates are also crucial for modeling approaches, to predict the roles of chytrids in altering the network structure and stability (Niquil et al., 2011), and in determining the zooplankton production (Miki et al., 2011). 
Table 1 | Density of zoospores or sporangia of chytrids in lakes.

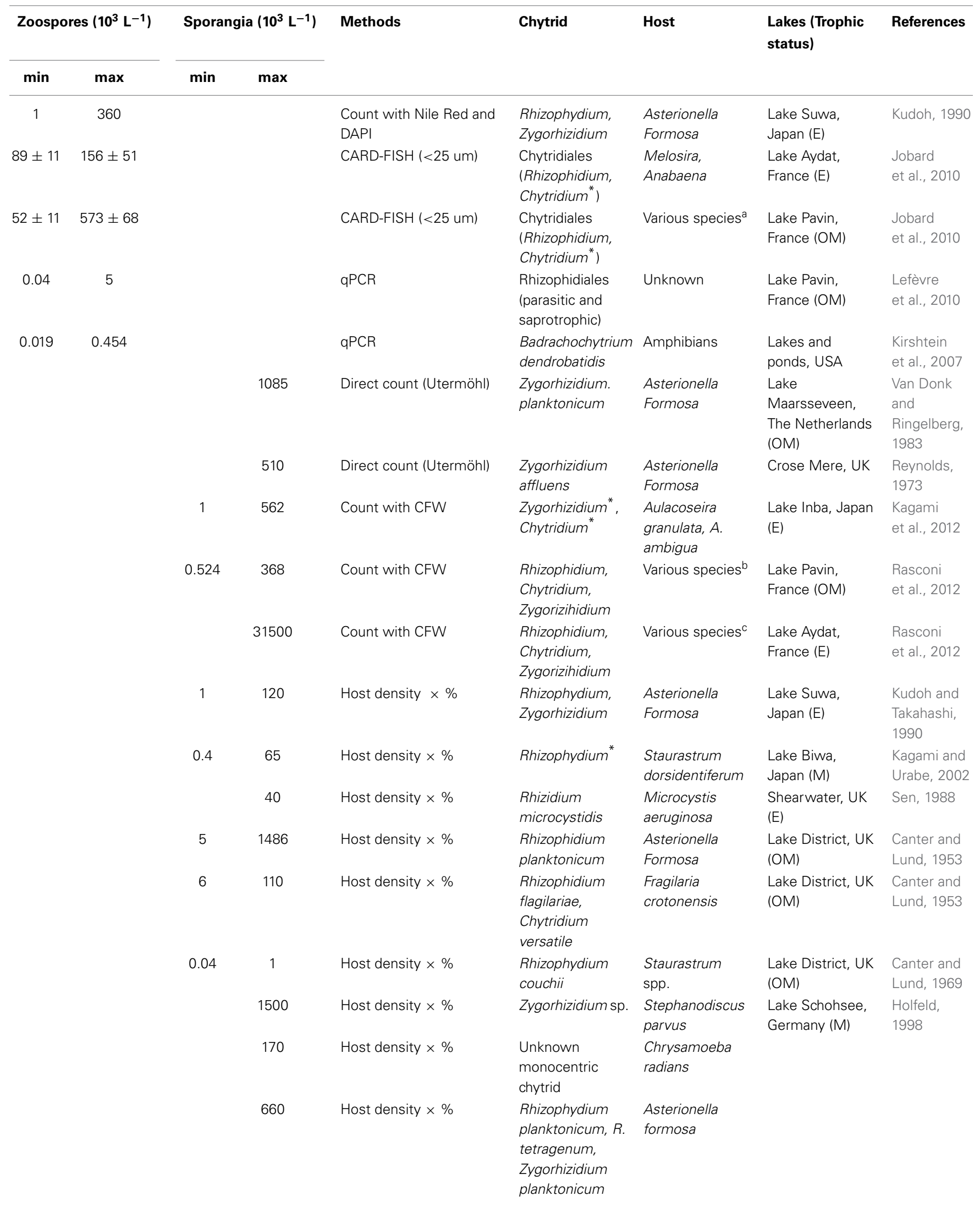


Table 1 | Continued

\begin{tabular}{|c|c|c|c|c|c|c|c|c|}
\hline \multicolumn{2}{|c|}{ Zoospores $\left(10^{3} \mathrm{~L}^{-1}\right)$} & \multicolumn{2}{|c|}{ Sporangia $\left(10^{3} L^{-1}\right)$} & \multirow[t]{2}{*}{ Methods } & \multirow[t]{2}{*}{ Chytrid } & \multirow[t]{2}{*}{ Host } & \multirow{2}{*}{$\begin{array}{l}\text { Lakes (Trophic } \\
\text { status) }\end{array}$} & \multirow[t]{2}{*}{ References } \\
\hline $\min$ & $\max$ & $\min$ & $\max$ & & & & & \\
\hline & & & 40 & Host density $\times \%$ & Zygorhizidium sp. & $\begin{array}{l}\text { Fragilaria } \\
\text { crotonensis }\end{array}$ & & \\
\hline & & & 9 & Host density $\times \%$ & $\begin{array}{l}\text { Zygorhizidium. } \\
\text { planktonicum }\end{array}$ & Synedra acus & & \\
\hline & & & 10 & Host density $\times \%$ & $\begin{array}{l}\text { Zygorhizidium } \\
\text { parallelosede }\end{array}$ & $\begin{array}{l}\text { Elakatothrix } \\
\text { genevensis }\end{array}$ & & \\
\hline
\end{tabular}

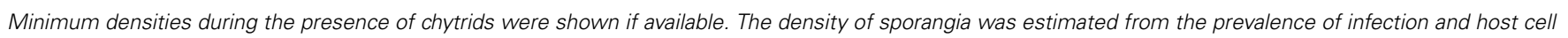
density data from the literature (shown as "Host density $\times \% "$ ).

CFW, calcofluor white; OM, oligo-mesotrophic; $M$, mesotrophic; E, eutrophic.

* Uncertain identification based on morphology or phylogeny.

a Asterionella, Fragilaria, Synedra, Staurastrum, Oocystis.

${ }^{b}$ Asterionella, Synedra, Staurastrum, Cyclotella, Fragilaria, Ankira, Melosira, Starodesmus, Chodatella, Ankystrodesms, Cylindrospermum, Oocystis.

${ }^{c}$ Asterionella, Synedra, Staurastrum, Cyclotella, Fragilaria, Ankira, Melosira, Oscillatoria, Microcystis, Fragilaria, Gomphosphaeria, Anabaena.

The "mycoloop" may occasionally play an important role in shaping aquatic systems, by altering the material flow (Figure 1). Traditionally, large inedible phytoplankton species are believed to be lost by sinking from the euphotic zone (Malone, 1981). However, if large phytoplankton are parasitized, then nutrients within host cells are instead consumed by chytrids, and can, in turn, be grazed by Daphnia through the mycoloop (Kagami et al., 2007a). In addition, large inedible colonies of phytoplankton may be fragmented into smaller pieces due to chytrid infections, making them more edible to zooplankton (Figure 1, Sime-Ngando, 2012). The trophic transfer efficiency from large phytoplankton to Daphnia would not change largely even if the heavily infected colonies are fragmented and grazed (i.e., after most of the host cells are consumed by chytrid). It would change, however, if the lightly infected host colonies are fragmented and grazed (i.e., before most of the host cells are consumed by chytrid) (SimeNgando, 2012). In this way, nutrients in host phytoplankton cells are partly incorporated into the food web in the euphotic zone, instead of sinking.

On the other hand, some of the infected host colonies may remain inedible for Daphnia, or even become less edible due to the aggregation of cells (Kagami et al., 2005, Figure 1) and may sink faster than single colonies. In addition, frustules of previously infected cells may sink faster than living cells (Kagami et al., 2006). In this way, sinking of frustules and aggregates of host cells may actually be facilitated by chytrid infections.

\section{PREDATION ON CHYTRIDS MAY SUPPRESS OUTBREAKS OF CHYTRIDS}

Predation on the free-living stages of parasites may result in reduced disease risk for hosts (Packer et al., 2003). Indeed, the presence of Daphnia can decrease chytrid infection intensity on phytoplankton (Kagami et al., 2004). Recent studies also revealed that Daphnia grazing on free-swimming zoospores of Batrachochytrium dendrobatidis can decrease the disease chytridiomycosis of amphibians (Hamilton et al., 2012; Searle et al., 2013).

\section{PHYTOPLANKTON—CHYTRID—ZOOPLANKTON INTERACTIONS}

Although a short-term experiment demonstrated that the direct trophic link from chytrid fungus to zooplankton (F-Z link) increased zooplankton growth (Kagami et al., 2007b), the effects of the F-Z link on food web dynamics is not easily predictable.

Considering that chytrid infections are common in large inedible phytoplankton species (Sommer, 1987; Kagami et al., 2007a), fungal parasitism may indirectly increase the abundance of small edible phytoplankton by altering resource competition. This may in turn enhance zooplankton production through grazing pathways via an "indirect mutualism" (Levine, 1976; Vandermeer, 1980). If the F-Z link then decreases the abundance of fungal zoospores (or fungal parasitism), it weakens the indirect mutualism between fungi and zooplankton, and will then decrease material transfer from small phytoplankton to zooplankton (indirect effect).

Therefore, the F-Z link may enhance zooplankton production through the mycoloop (direct effects), while it may also decrease zooplankton production by weakening indirect mutualism (indirect effect). By using a simple food web model, we successfully evaluated the effects of parasitic chytrids (fungal parasitism) and the F-Z link (both direct and indirect effects) on food web dynamics (Miki et al., 2011). In summary, presence of the F-Z link caused unexpected indirect effects in the food web, and was an important determinant for the stability of the system (see the following section for more detail). The model indicated that the high growth efficiency and high nutritional quality of fungi were crucial for the F-Z link to increase zooplankton production. The model also indicated that the contribution of the mycoloop (material transfer via the F-Z link) to zooplankton production increased with nutrient availability and depended on the system stability. This 
implies that neglecting the dynamical aspect of the system will lead to inaccurate estimates of material and energy fluxes. In the following section, we will review the theoretical approaches in detail to evaluate the roles of parasitic fungi in aquatic food webs.

\section{MULTIFACETED IMPACTS OF FUNGUS-ZOOPLANKTON INTERACTIONS ON FOOD WEB DYNAMICS: LESSONS FROM DYNAMICAL MODELS}

There are two modeling approaches for describing the structure, dynamics, and fluxes of material and energy in food webs and ecosystems: steady state models and dynamical models. The steady state model (or linear model) is a powerful tool in ecosystem sciences to quantitatively estimate material fluxes with limited observations (Vezina, 1989). For example, it has been used to estimate the impacts on carbon fluxes in aquatic ecosystems, of the microbial loop (e.g., Anderson and Ducklow, 2001; Anderson and Tang, 2010), bacteriophage (Fuhrman, 1999; Motegi et al., 2009), and the food web structure (Niquil et al., 2006). Recent studies also quantified the impact of chytrid fungi in lake carbon fluxes using this modeling approach with inverse estimates of fluxes (Grami et al., 2011; Niquil et al., 2011). On the other hand, the dynamical model, which often requires a larger number of parameters and more specific mathematical formulations for inter-compartment interactions (e.g., trophic and competitive interactions), can provide information about both the steady state structure and non-steady state dynamics of the food web. Here, we would like to highlight the three major impacts of the F-Z link on the food web; (1) effect on food web structure and zooplankton production, (2) influence on system stability, and (3) contribution to material fluxes (mycoloop), elucidated by dynamical food web models (Miki et al., 2011; Gerla et al., 2013). Since conclusions are often different between steady state models and dynamic models, we will compare these two modeling approaches.

1. Effects of the F-Z link on food web structure and zooplankton production: The dynamical model can predict the unexpected consequences of nonlinear effects of adding or removing a specific trophic linkage or a specific player in the structure of the food web (Pimm, 1991). In our case, we added/removed two trophic linkages; fungal parasitism and the F-Z link (Miki et al., 2011) for a detailed comparison among three scenarios: the system without parasitic fungi, the system with fungal parasitism but without the F-Z link, and the system with both fungal parasitism and the F-Z link. The dynamical model predicts that the F-Z link indirectly lowers the abundance of small phytoplankton, altering the food web structure (Miki et al., 2011). This prediction agrees with the predicted decline in picophytoplankton production in Lake Pavin steady state model (Grami et al., 2011). Similarly, both models predict the positive impact of fungal parasitism and F-Z link on zooplankton production and biomass. This implies robust positive impacts of fungi on trophic transfer to higher trophic levels. Some scenarios in the dynamical model have not been explored in the framework of the steady state model. The dynamical model predicted that the F-Z link can unexpectedly reduce the production and biomass of zooplankton compared to a system with fungal parasitism but without an active F-Z link (Miki et al., 2011). This is unexpected considering the apparent (direct) benefit of the F-Z link to zooplankton. This occurs through an indirect effect; the F-Z link increases the host population (large inedible phytoplankton) via a top-down cascade, which in turn decreases the population of non-host, small edible phytoplankton through intensified resource competition (Figure 2). In particular, when the growth efficiency of parasitic fungi on host tissues and the nutrient quality of zoospores for zooplankton are not large enough (i.e., the metabolic loss through these trophic interactions is large) or productivity (nutrient availability) in the system is low, then indirect negative effects are greater than positive direct benefits and the F-Z link then causes a reduction in the zooplankton biomass and production (compare A vs. B in Figure 2). In order to better quantify the role of fungal parasitism and the F-Z link separately, three scenarios (the system without fungi, the system with fungal parasitism but without trophic transfer from fungi to zooplankton, and the system with both fungal parasitism and F-Z link) should be compared even with the steady state model approach.

2. Influence of the F-Z link on system stability: Although theoretical metrics for steady-state ecosystem structure can predict the complexity of the network and imply the stability of the system (Morris et al., 2005; Ulanowicz et al., 2009; Grami et al., 2011; Niquil et al., 2011), consequences of nonlinearity in trophic interactions on system stability can be evaluated more directly in a dynamical model. When the trophic interaction between host phytoplankton and parasitic fungi is parameterized by a prey-predator type model with non-linear functional response (e.g., Holling type II functional response) (Miki et al., 2011) or more explicitly parameterized by a hostparasite type model with SIV formulation (susceptible host, infected host, and free-living vector; Gerla et al., 2013), food web dynamics are predicted to be less stable than a model with a simple Lotka-Volterra type prey-predator functional response (Miki et al., 2011). In addition, although the network analysis implied a stabilization of the system by fungi (Grami et al., 2011; Niquil et al., 2011), the dynamical model clearly demonstrated that the presence of the F-Z link (Figure S1, Miki et al., 2011) or the presence of a host-fungus interaction itself (Figure 3, Gerla et al., 2013) can destabilize the system, especially in eutrophic conditions. The dependency of fungal zoospore production rate on host physiology and activity (e.g., nutrient uptake rate) is also proposed as the destabilizing factor (Gerla et al., 2013).

3. Contribution of the mycoloop to material fluxes: the above consideration on system stability implies that it may be risky to assume that the roles of parasitic fungi in material fluxes estimated by steady state model equates to their role under nonsteady state conditions. A non-steady state dynamic of the food web may be caused internally by nonlinear trophic interactions (as mentioned above) or externally forced by environmental fluctuations. A steady-state model is able to provide a snapshot estimate of fluxes in an ecosystem even under non-steadystate conditions if the instantaneous mass accumulation rate in each ecosystem component is not too large (quasi-steady 

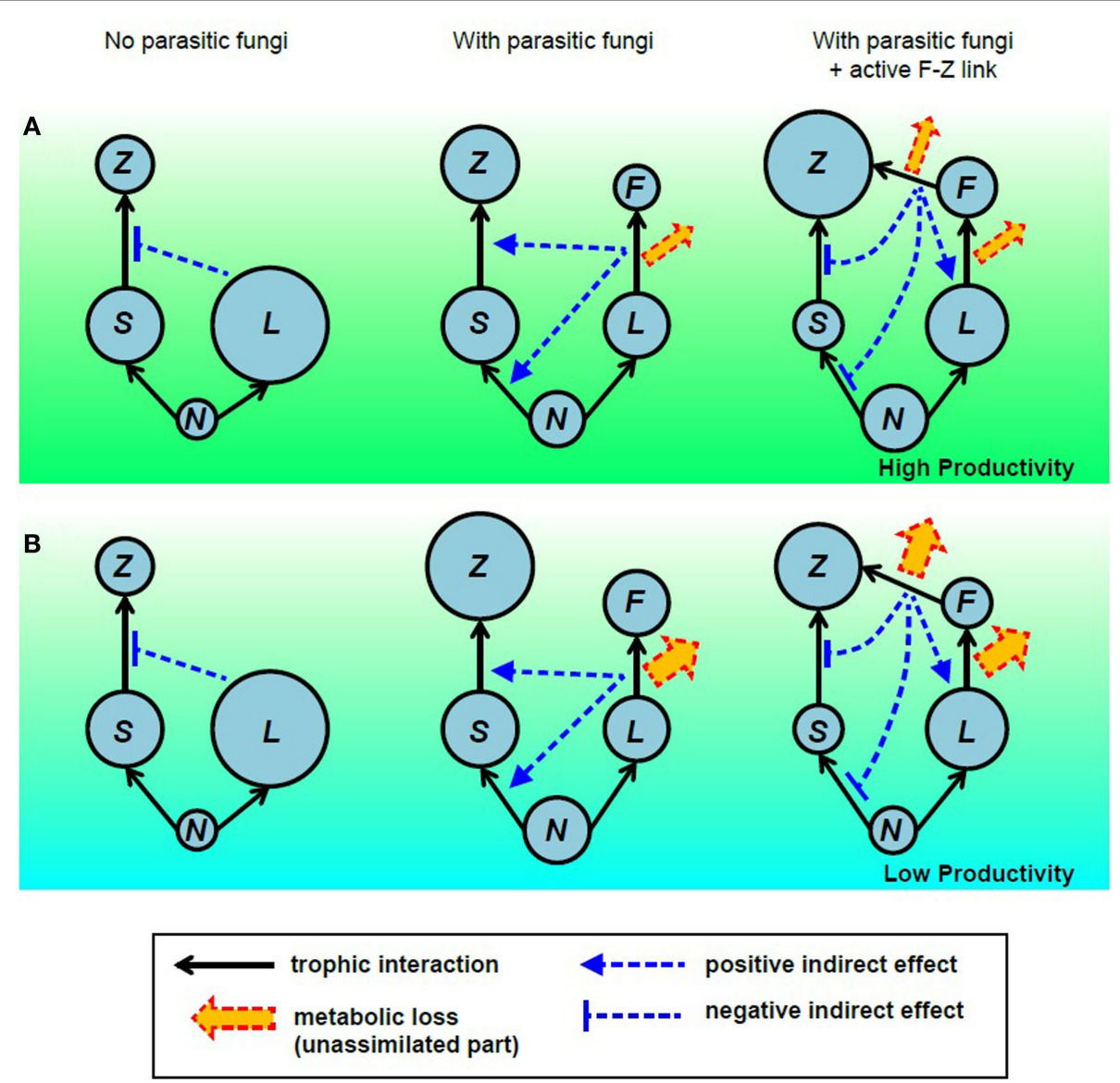

FIGURE 2 | Indirect effects of the F-Z link and their feedback on zooplankton. The net effects of the fungus-zooplankton link on zooplankton biomass production depends on three conditions: the growth efficiency of fungi on the host, the growth efficiency of zooplankton consuming fungi, and the nutrient supply in the system. $\boldsymbol{N}$, inorganic nutrient; $\boldsymbol{L}$, large phytoplankton; $\boldsymbol{S}$, small phytoplankton; $\boldsymbol{F}$, chytrid fungi; and $\boldsymbol{Z}$, zooplankton. (A) When these growth efficiencies are high, in other words, when the metabolic loss of fungi or metabolic loss of zooplankton is low, or the system productivity is high, the F-Z link increases zooplankton biomass production, compared to the system with fungal parasitism only. (B) When metabolic losses are high or the system productivity is low, the F-Z link decreases zooplankton biomass production compared to the system with fungal parasitism only. More quantitative results are shown in Miki et al. (2011). state assumption). However, the steady state assumption tends to significantly overestimate (a factor of 2-10) the annual averaged contribution of the F-Z link under seasonal fluctuations (Miki et al., 2011; Figure 3). More specifically, the predicted relative contribution of fungi to zooplankton production from the dynamical model under a stable environment is $38.6 \%$ when the growth efficiency of fungi on host phytoplankton is assumed to be $75 \%$ and the total phosphorus is $100 \mu \mathrm{gPL}^{-1}$ (Figure 3). This prediction is comparable to the estimate of the contribution of fungal zoospores in the total diet of microzooplankton in ologimesotrophic Lake Pavin (38\%) (Grami et al., 2011). However, an introduction of seasonality into the dynamical model lowers the contribution of fungi to $19.9 \%$. Such an overestimate is a general feature in nonlinear systems. When the trophic flux $(F)$ is proportional to the abundance of resources $(R)$ and consumers $(C): F=a R C$ where $a$ is the consumption coefficient, then the average flux $(\overline{F(t)})$ is not equivalent to the product of the averages $\overline{R(t)}$ and $\overline{C(t)}$. Instead, we have $\overline{F(t)}=a[\overline{R(t)} \cdot \overline{C(t)}+\operatorname{Cov}(R(t), C(t))]$, implying that neglecting the impacts of asynchronous population dynamics of resources and consumers $(\operatorname{Cov}(R, C)<0)$ is the source of the overestimation with a steady-state assumption.

Combination of steady state models and dynamical models are a promising approach to greatly improve our understanding of the roles of parasitic fungi.

\section{FUTURE PERSPECTIVES MOLECULAR TOOLS}

Recent advances in molecular methods enable us to investigate the species composition of microorganisms. Indeed, several methods, such as PCR-DGGE, clone libraries, FISH, and qPCR have been applied to describe the species composition and biomass of certain species of parasitic chytrids (Jobard et al., 2010; Lefèvre et al., 2010; Kagami et al., 2012; Marano et al., 2012, Maier et al., under revision). In addition, next generation sequencing 


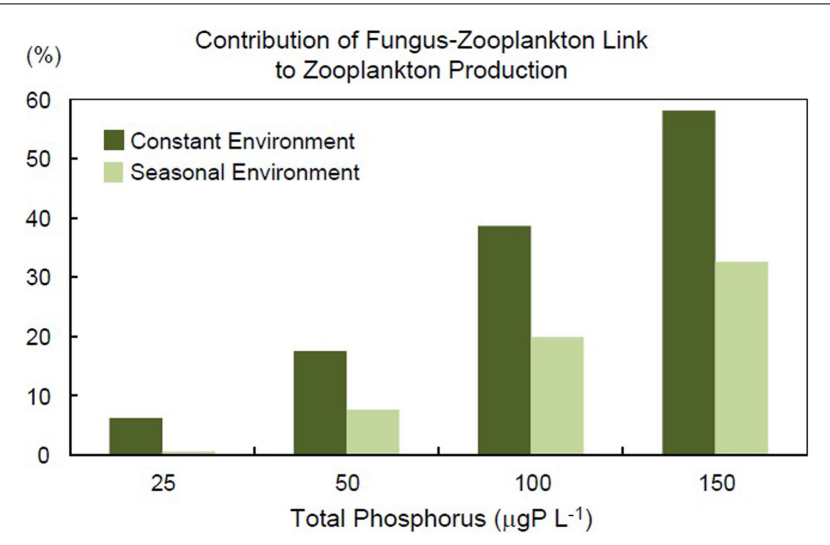

FIGURE 3 | Comparison of the contribution of the mycoloop pathway to zooplankton production under constant and seasonal environments. The relative percent contribution of the mycoloop pathway (large phytoplankton $\rightarrow$ parasitic fungi $\rightarrow$ zooplankton) to total zooplankton biomass production under constant and seasonal environmental conditions was calculated as the ratio of the F-Z link nutrient flux to zooplankton compared to the total nutrient flux to zooplankton (nutrient flux from the F-Z link plus nutrient flux from small phytoplankton) (see also Figure 2). The ratios of the contribution of the mycoloop under constant environmental conditions compared to that under seasonal environmental conditions was calculated for concentrations of total phosphorus (TP) $=25.0,50.0,100$, $150 \mu \mathrm{gP} \mathrm{L}^{-1}$ to be $10.3,2.30,1.94,1.78$. TP in the model ecosystem was calculated by the average phosphorus supply $I_{0}$ divided by the turnover rate of the system (0.05/day). The daily fluctuation in the phosphorus supply $I(t)$ is given by $/(t)=I_{0}[1.0+0.5 \sin (2 \pi t / 365)]$ for the seasonal environment; the maximum deviation from average is $\pm 50 \%$. Modified from Miki et al. (2011). will be beneficial for the analysis of fungal community structures. However, since the DNA database of aquatic fungi is scarce, especially for the parasitic fungi (chytrids), it is difficult to determine species composition and function (e.g., parasitic or saprotrophic) by analyzing environmental DNA alone. In addition, choosing the right primer sets are essentially important when examining the species composition by molecular tools (Wurzbacher et al., 2010, Ishii et al., in review). Therefore, prior to applying advanced molecular tools, we first need to build a robust database, especially for the parasitic chytrids. Culturing, single cell PCR methods, and whole genome sequencing will aid in having a better understanding of the community structure and function of parasitic fungi wide-ranging ecosystems.

\section{OTHER POSSIBLE MYCOLOOPS}

In addition to parasitic chytrids, saprotrophic chytrids may also play important roles in aquatic food webs. For instance, pollen deposition into lakes may not be utilized directly by zooplankton, but can be decomposed/consumed by saprotrophic chytrids (Masclaux et al., 2011, 2013). Grazing of zoospores released from pollen may then function as another "mycoloop" (Figure 4).

Recently discovered fungi, the Cryptomycota, exhibit a similar life cycle to chytrids including a free-swimming stage, and are also known to infect phytoplankton (Jones et al., 2011). In marine environments, some Chytridiomycota or zoosporic fungal-like protists such as Labyrinthulomycota are also known to infect marine phytoplankton (Raghukumar, 2002; Gleason et al., 2011), and may play important roles in marine food web dynamics (Raghukumar, 2002). These results indicate the existence of

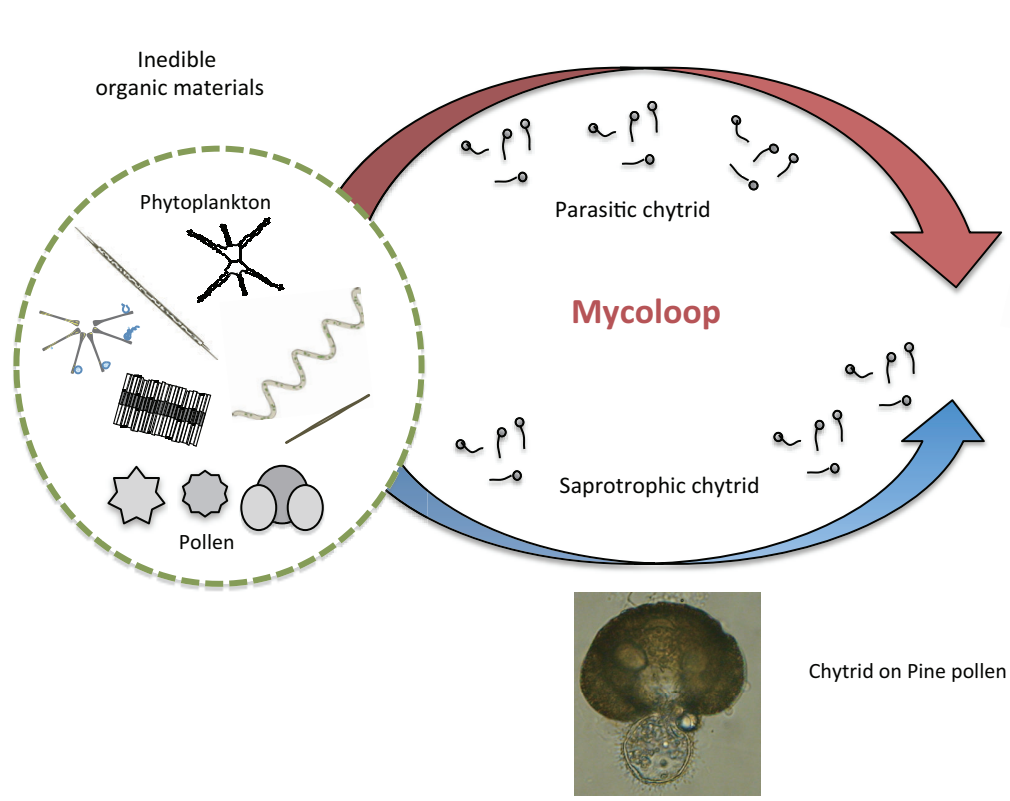

Zooplankton
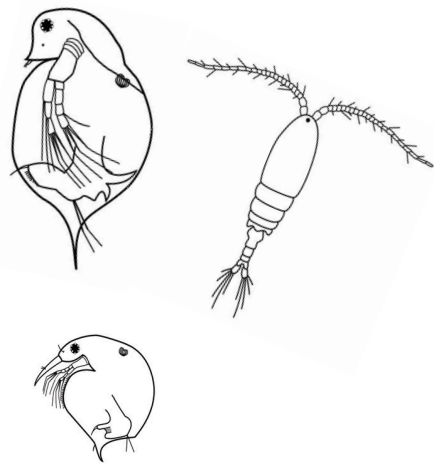

functioning as another "mycoloop." In addition to chytrids, other zoosporic fungi or fungal-like protists, such as Cryptomycota and Labyrinthulomycota, can infect phytoplankton or consume large inedible organic material, which environments. Saprotrophic chytrids may play important roles in aquatic food webs, by decomposing inedible organic material such as pollens. may be grazed by zooplankton in freshwater and marine environments. 
other possible mycoloops in freshwater and marine ecosystems via the route of free-swimming zoospores of newly discovered Chytridiomycota, Cryptomycota, or Labyrinthulomycota.

\section{ACKNOWLEDGMENTS}

We are grateful to Prof. Hans-Peter Grossart for his valuable discussions and encouragements. We thank M. Maier for correcting English. This study was supported by a research fellowship from the Japan Society of the Promotion of Science.

\section{REFERENCES}

Anderson, T. R., and Ducklow, H. W. (2001). Microbial loop carbon cycling in ocean environments studies using a simple steady-state model. Aquat. Microb. Ecol. 26, 37-49. doi: 10.3354/ame026037

Anderson, T. R., and Tang, K. W. (2010). Carbon cycling and POC turnover in the mesopelagic zone of the ocean: insights from a simple model. Deep Sea Res. Part II Top. Stud. Oceanogr. 57, 1581-1592. doi: 10.1016/j.dsr2.2010. 02.024

Bruning, K. (1991). Infection of the diatom Asterionella by a chytrid.I. Effects of light on reproduction and infectivity of the parasite. J. Plankton Res. 13, 103-117. doi: 10.1093/plankt/13.1.103

Canter, H. M. (1967). Studies on British chytrids XXVI. A critical examination of Zygorhizidium melosirae Canter and Z. planktonicum Canter. Biol. J. Linn. Soc. 60, 85-97. doi: 10.1111/j.1095-8339.1967.tb00081.x

Canter, H. M., and Lund, J. W. G. (1953). Studies on plankton parasites II. The parasitism of diatoms with special reference to lakes in the English Lake District. Trans. Br. Mycol. Soc. 36, 13-37. doi: 10.1016/S0007-1536(53) 80038-0

Canter, H. M., and Lund, J. W. G. (1969). Parasitism of planktonic desmids by fungi. Österr. Bot. Z. 116, 351-377. doi: 10.1007/BF01379634

Fuhrman, J. A. (1999). Marine viruses and their biogeochemical and ecological effects. Nature 399, 541-548. doi: 10.1038/21119

Gerla, D. J., Gsell, A. S., Kooi, B. W., Ibelings, B. W., Van Donk, E., and Mooij, W. M. (2013). Alternative states and population crashes in a resource-susceptibleinfected model for planktonic parasites and hosts. Freshw. Biol. 58, 538-551. doi: 10.1111/fwb. 12010

Gleason, F. H., Kagami, M., Lefevre, E., and Sime-Ngando, T. (2008). The ecology of chytrids in aquatic ecosystems: roles in food web dynamics. Fungal Biol. Rev. 22, 17-25. doi: 10.1016/j.fbr.2008.02.001

Gleason, F. H., Küpper, F. C., Amon, J. P., Picard K., Gachon, C. M. M., Marano, A. V., et al. (2011). Zoosporic true fungi in marine ecosystems: a review. Mar. Freshw. Res. 62, 383-393. doi: 10.1071/MF10294

Gonzalez, J. M., and Suttle, C. A. (1993). Grazing by marine nanoflagellates on viruses and virus-sized particles - Ingestion and digestion. Mar. Ecol. Prog. Ser. 94, 1-10. doi: 10.3354/meps094001

Grami, B., Rasconi, S., Niquil, N., Jobard, M., Saint-Béat, B., and Sime-Ngando, T. (2011). Functional effects of parasites on food web properties during the spring diatom bloom in Lake Pavin: a linear inverse modeling analysis. PLoS ONE 6:e23273. doi: 10.1371/journal.pone.0023273

Hamilton, P. T., Richardson, J. M. L., and Anholt, B. R. (2012). Daphnia in tadpole mesocosms: trophic links and interactions with Batrachochytrium dendrobatidis. Freshw. Biol. 57, 676-683. doi: 10.1111/j.1365-2427.2011.02731.x

Hatcher, M. J., and Dunn, A. M. (2011). Parasites in Ecological Communities: From Interactions to Ecosystems. Cambridge: Cambridge University Press. doi: 10.1017/СBO9780511987359

Holfeld, H. (1998). Fungal infections of the phytoplankton: seasonality, minimal host density, and specificity in a mesotrophic lake. New Phytol. 138, 507-517. doi: 10.1046/j.1469-8137.1998.00126.x

Jobard, M., Rasconi, S., and Sime-Ngando, T. (2010). Fluorescence in situ hybridization of uncultured zoosporic fungi: testing with clone-FISH and application to freshwater samples using CARD-FISH. J. Microbiol. Methods 83, 236-243. doi: 10.1016/j.mimet.2010.09.006

Johnson, P. T. J., Dobson, A., Lafferty, K. D., Marcogliese, D. J., Memmott, J., Orlofske, S. A., et al. (2010). When parasites become prey: ecological and epidemiological significance of eating parasites. Trends Ecol. Evol. 25, 362-371. doi: 10.1016/j.tree.2010.01.005
Jones, M. D. M., Forn, I., Gadelha, C., Egan, M. J., Bass, D., Massana, R., et al. (2011). Discovery of novel intermediate forms redefines the fungal tree of life. Nature 474, 200-203. doi: 10.1038/nature09984

Kagami, M., Amano, Y., and Ishii, N. (2012). Community structure of planktonic fungi and the impact of parasitic chytrids on phytoplankton in Lake Inba, Japan. Microb. Ecol. 63, 358-368. doi: 10.1007/s00248-011-9913-9

Kagami, M., de Bruin, A., Ibelings, B. W., and Van Donk, E. (2007a). Parasitic chytrids: their effects on phytoplankton communities and food-web dynamics. Hydrobiologia 578, 113-129. doi: 10.1007/s10750-006-0438-z

Kagami, M., Gurung, T. B., Yoshida, T., and Urabe, J. (2006). To sink or to be lysed: contrasting fate of two large phytoplankton species in Lake Biwa. Limnol. Oceanogr. 51, 2775-2786. doi: 10.4319/lo.2006.51.6.2775

Kagami, M., Helmsing, N. R., and Van Donk, E. (2011). Parasitic chytrids could promote copepod survival by mediating material transfer from inedible diatoms. Hydrobiologia 659, 49-54. doi: 10.1007/s10750-010-0274-z

Kagami, M., Ibelings, B. W., de Bruin, A., and Van Donk, E. (2005). Vulnerability of Asterionella formosa to Daphnia grazing: impact of a fungal parasite. Verh. Int. Verein Limnol. 29, 350-354.

Kagami, M., and Urabe, J. (2002). Mortality of the planktonic desmid, staurastrum dorsidentiferum, due to interplay of fungal parasitism and low light conditions. Verh. Int. Verein Limnol. 28, 1001-1005.

Kagami, M., Van Donk, E., de Bruin, A., Rijkeboer, M., and Ibelings, B. W. (2004). Daphnia can protect diatoms from fungal parasitism. Limonol. Oceanogr. 49, 680-685. doi: 10.4319/lo.2004.49.3.0680

Kagami, M., Von Elert, E., Ibelings, B. W., de Bruin, A., and Van Donk, E. (2007b). The parasitic chytrid, Zygorhizidium, facilitates the growth of the cladoceran zooplankter, Daphnia, in cultures of the inedible alga, Asterionella. Proc. R. Soc. B Biol. Sci. 274, 1561-1566. doi: 10.1098/rspb.2007.0425

Kagami, M., Yoshida, T., Gurung, T., and Urabe, J. (2002). Direct and indirect effects of zooplankton on algal composition in in situ grazing experiments. Oecologia 133, 356-363. doi: 10.1007/s00442-002-1035-0

Kirshtein, J. D., Anderson, C. W., Wood, J. S., Longcore, J. E., and Voytek, M. A. (2007). Quantitative PCR detection of Batrachochytrium dendrobatidis DNA from sediments and water. Dis. Aquat. Organ. 77, 11-15. doi: 10.3354/dao01831

Knisely, K., and Geller, W. (1986). Selective feeding of 4 zooplankton species on natural lake phytoplankton. Oecologia 69, 86-94. doi: 10.1007/BF0 0399042

Kudoh, S. (1990). Studies on the Population Control Mechanisms of a Planktonic Diatom, Asterionella formosa Hassall, by Fungal Parasitism in Natural Waters. Tokyo: University of Tokyo.

Kudoh, S., and Takahashi, M. (1990). Fungal control of population changes of the planktonic diatom Asterionella formosa in a shallow eutrophic lake. J. Phycol. 26, 239-244. doi: 10.1111/j.0022-3646.1990.00239.x

Kuris, A. M., Hechinger, R. F., Shaw, J. C., Whitney, K. L., Aguirre-Macedo, L., Boch, C. A., et al. (2008). Ecosystem energetic implications of parasite and free-living biomass in three estuaries. Nature 454, 515-518. doi: 10.1038/nature06970

Lafferty, K. D. (2006). Parasites dominate food web links. Proc. Natl. Acad. Sci. U.S.A. 103, 11211-11216. doi: 10.1073/pnas.0604755103

Lafferty, K. D., Arim, M., Briggs, J., De Leo, G., Dobson, P., Dunne, J. A., et al. (2008). Parasites in food webs: the ultimate missing links. Ecol. Lett. 11, 533-546. doi: 10.1111/j.1461-0248.2008.01174.x

Lefèvre, E., Bardot, C., Noël, C., Carrias, J. F., Viscogliosi, E., Amblard, C., et al. (2007). Unveiling fungal zooflagellates as members of freshwater picoeukaryotes: evidence from a molecular diversity study in a deep meromictic lake. Environ. Microbiol. 9, 61-71. doi: 10.1111/j.1462-2920.2006.01111.x

Lefèvre, E., Jobard, M., Venisse, J. S., Bec, A., Kagami, M., Amblard, C., et al. (2010). Development of a real-time PCR assay for quantitative assessment of uncultured freshwater zoosporic fungi. J. Microbiol. Methods 81, 69-76. doi: 10.1016/j.mimet.2010.02.002

Lepère, C., Domaizon, I., and Debroas, D. (2008). Unexpected importance of potential parasites in the composition of the freshwater small-eukaryote community. Appl. Environ. Microbiol. 74, 2940-2949. doi: 10.1128/AEM.01156-07

Levine, S. H. (1976). Competitive interactions in ecosystems. Am. Nat. 110, 903-910. doi: $10.1086 / 283116$

Malone, T. C. (1981). "Algal size," in The Physiological Ecology of Phytoplankton, ed I. Morris (Berkeley; New York, NY: University of California Press), 433-463.

Marano, A. V., Gleason, F. H., Bärlocher, F., Pires-Zottarelli, C. L. A., Lilje, O., Schmidt, S. K., et al. (2012). Quantitative methods for the analysis of zoosporic fungi. J. Microbiol. Methods 89, 22-32. doi: 10.1016/j.mimet.2012.02.003 
Marcogliese, D. J., and Cone, D. K. (1997). Food webs: a plea for parasites. Trends Ecol. Evol. 12, 394. doi: 10.1016/S0169-5347(97)01080-X

Masclaux, H., Bec., A., Kagami, M., Perga, M. E., Sime-Ngando, T., Desvilettes, C., et al. (2011). Food quality of anemophilous plant pollen for zooplankton. Limnol. Oceanogr. 56, 939-946. doi: 10.4319/lo.2011.56.3.0939

Masclaux, H., Perga, M. E., Kagami, M., Desvilettes, C., Bourdier, G., and Bec, A. (2013). How pollen organic matter enters freshwater food webs. Limnol. Oceanogr. 58, 1185-1195. doi: 10.4319/lo.2011.56.3.0939

Miki, T., Takimoto, G., and Kagami, M. (2011). Roles of parasitic fungi in aquatic food webs: a theoretical approach. Freshw. Biol. 56, 1173-1183. doi: $10.1111 / j .1365-2427.2010 .02562 . x$

Morris, J. T., Christian, R. R., and Ulanowicz, R. E. (2005). "Analysis of size and complexity of randomly constructed food webs by information theoretic metrics," Aquatic Food Webs: An Ecosystem Approach, eds A. Belgrano, U. M. Scharler, J. Dunne, and R. E. Ulanowicz (Oxford: Oxford University Press), 73-85. doi: 10.1093/acprof:oso/9780198564836.003.0008

Motegi, C., Nagata, T., Miki, T., Weinbauer, M. G., Legendre, L., and Rassoulzadegan, F. (2009). Viral control of bacterial growth efficiency in marine pelagic environments. Limnol. Oceanogr. 54, 1901-1910. doi: 10.4319/lo.2009.54.6.1901

Niquil, N., Bartoll, G., Urabe, J., Jackson, G. A., Legendre, L., Dupuy, C., et al. (2006). Carbon steady-state model of the planktonic food web of Lake Biwa, Japan. Freshw. Biol. 51, 1570-1585. doi: 10.1111/j.1365-2427.2006. 01595.x

Niquil, N., Kagami, M., Urabe, J., Christaki, U., Viscogliosi, E., and Sime-Ngando, T. (2011). Potential role of fungi in plankton food web functioning and stability: a simulation analysis based on Lake Biwa inverse model. Hydrobiologia 659, 65-79. doi: 10.1007/s10750-010-0308-6

Packer, C., Holt, R. D., Hudson, P. J., Lafferty, K. D., and Dobson, A. P. (2003). Keeping the herds healthy and alert: implications of predator control for infectious disease. Ecol. Lett. 6, 797-802. doi: 10.1046/j.1461-0248.2003.00500.x

Pimm, S. L. (1991). The Balance of Nature?: Ecological Issues in the Conservation of Species and Communities. Chicago: University of Chicago Press.

Polis, G. A., and Strong, D. R. (1996). Food web complexity and community dynamics. Am. Nat. 147, 813-846. doi: 10.1086/285880

Raghukumar, S. (2002). Ecology of the marine protists, the Labyrinthulomycetes (Thraustochytrids and Labyrinthulids). Eur. J. Protistol. 38, 127-145. doi: 10.1078/0932-4739-00832

Rasconi, S., Niquil, N., and Sime-Ngando, T. (2012). Phytoplankton chytridiomycosis: community structure and infectivity of fungal parasites in aquatic ecosystems. Environ. Microbiol. 14, 2151-2170. doi: 10.1111/j.1462-2920.2011.02690.x

Reynolds, C. S. (1973). The seasonal periodicity of planktonic diatoms in a shallow eutrophic lake. Freshw. Biol. 3, 89-110. doi: 10.1111/j.1365-2427.1973.tb00065.x

Searle, C. L., Mendelson, J. R., Green, L. E., and Duffy, M. A. (2013). Daphnia predation on the amphibian chytrid fungus and its impacts on disease risk in tadpoles. Ecol. Evol. 3, 4129-4138. doi: 10.1002/ece3.777

Sen, B. (1988). Fungal parasitism of planktonic algae in Shearwater IV. Parasitic occurrence of a new chytrid species on the blue-green alga. Arch. Fur Hydrobiol. $79,177-184$.
Sherr, E. B., and Sherr, B. F. (1983). Double-staining epifluorescence technique to assess frequency of dividing cells and bacteriovory in natural populations of heterotrophic microprotozoa. Appl. Environ. Microbiol. 46, 1388-1393.

Sime-Ngando, T. (2012). Phytoplankton chytridiomycosis: fungal parasites of phytoplankton and their imprints on the food web dynamics. Front. Microbiol. 3:361. doi: $10.3389 /$ fmicb.2012.00361

Sime-Ngando, T., Lefèvre, E., and Gleason, F. H. (2011). Hidden diversity among aquatic heterotrophic flagellates: ecological potentials of zoosporic fungi. Hydrobiologia 659, 5-22. doi: 10.1007/s10750-010-0230-y

Sommer, U. (1987). Factors controlling the seasonal variation in phytoplankton species composition - a case study for a deep, nutrient rich lake. Prog. Phycol. Res. 5, 124-178.

Sparrow, F. K. (1960). Aquatic Phycomycetes. 2nd Edn. Michigan: University of Michigan Press.

Thieltges, D. W., Amundsen, P. A., Hechinger, R. F., Johnson, P. T. J., Lafferty, K. D., Mouritsen, K. N., et al. (2013). Parasites as prey in aquatic food webs: implications for predator infection and parasite transmission. Oikos 122, 1473-1482. doi: 10.1111/j.1600-0706.2013.00243.x

Thomas, F., Renaud, F., and Guegan, J. (2005). Parasitism and Ecosystems. Oxford: Oxford University Press. doi: 10.1093/acprof:oso/9780198529873.001.0001

Ulanowicz, R. E., Goerner, S. J., Lietaer, B., and Gomez, R. (2009). Quantifying sustainability: resilience, efficiency and the return of information theory. Ecol. Complex. 6, 27-36. doi: 10.1016/j.ecocom.2008.10.005

Vandermeer, J. (1980). Indirect mutualism: variations on a theme by Stephen Levine. Am. Nat. 116, 441-448. doi: 10.1086/283637

Van Donk, E., and Ringelberg, J. (1983). The effect of fungal parasitism on the succession of diatoms in Lake Maarsseveen-I (The Netherlands). Freshw. Biol. 13, 241-251. doi: 10.1111/j.1365-2427.1983.tb00674.x

Vezina, A. F. (1989). "Construction of flow networks using inverse methods," in Network Analysis in Marine Ecology, eds F. Wolff, J. G. Field, and K. H. Mann (Berlin: Springer), 62-81.

Wurzbacher, C., Bärlocher, F., and Grossart, H. (2010). Fungi in lake ecosystems. Aquat. Microb. Ecol. 59, 125-149. doi: 10.3354/ame01385

Conflict of Interest Statement: The authors declare that the research was conducted in the absence of any commercial or financial relationships that could be construed as a potential conflict of interest.

Received: 24 January 2014; accepted: 27 March 2014; published online: 22 April 2014. Citation: Kagami M, Miki T and Takimoto G (2014) Mycoloop: chytrids in aquatic food webs. Front. Microbiol. 5:166. doi: 10.3389/fmicb.2014.00166

This article was submitted to Aquatic Microbiology, a section of the journal Frontiers in Microbiology.

Copyright (-) 2014 Kagami, Miki and Takimoto. This is an open-access article distributed under the terms of the Creative Commons Attribution License (CC BY). The use, distribution or reproduction in other forums is permitted, provided the original author(s) or licensor are credited and that the original publication in this journal is cited, in accordance with accepted academic practice. No use, distribution or reproduction is permitted which does not comply with these terms. 